\title{
Conceptual Design of New Bio-inspired Automotive Side-Door Impact Beam
}

\author{
M. A. Shaharuzaman, S. M. Sapuan, M. R. Mansor, M. Y. M. Zuhri
}

\begin{abstract}
Side-door impact beam has been introduced to the passenger vehicles to reduce the door intrusion into passenger compartment during side impact collision. This study aims to develop the new bio-inspired design concepts of composites side-door impact beam. The integrated Theory of Inventive Principle - Function Oriented Search (TRIZ-FOS) and Biomimetics method is the idea generation technique applied in this research to develop the design concepts while the analysis of the generated design concepts using impact test simulation in finite element analysis (FEA) is the method to compare their performances. TRIZ (FOS) - Biomimetics method helps to transfer the nature technology into engineering problems and shows that it can generates five design concepts based on three nature technology which is toucan beak, pomelo peel and hedgehog spine in this study. The FEA analysis method then compared their strength, deformation, energy absorption and weight. In a conclusion, the integrated method of TRIZ (FOS) Biomimetics helps engineers in generating the nature technology ideas to solve engineering problems using a structured method as proposed in this study while the FEA method really helps engineers to obtain the performances data for the design generated before proceed to the next step of product development process.
\end{abstract}

Keywords : Biomimetics, Function Oriented Search (FOS), side-door impact beam, Theory of Inventive Problem Solving (TRIZ).

\section{INTRODUCTION}

General Motors have introduced automotive side-door impact beam in late 1960's to prevent the passenger's compartment area from intrusion during the side impact collision [1]. The numbers of fatality reduction are not significant until the National Highway Traffic Safety Administration (NHTSA) improved the regulation [2]. Started in 1990, NHTSA introduced Moving Deformable

Revised Manuscript Received on February 05, 2020.

* Correspondence Author

M. A. Shaharuzaman*, Centre for Advanced Research on Energy, Faculty of Mechanical Engineering, Universiti Teknikal Malaysia Melaka, Hang Tuah Jaya, 76100 Durian Tunggal, Melaka, Malaysia.

S. M. Sapuan, Advanced Engineering Materials and Composites Research Centre, Department of Mechanical and Manufacturing Engineering, Universiti Putra Malaysia, 43400 UPM Serdang, Selangor, Malaysia.

M. R. Mansor, Centre for Advanced Research on Energy, Faculty of Mechanical Engineering, Universiti Teknikal Malaysia Melaka, Hang Tuah Jaya, 76100 Durian Tunggal, Melaka, Malaysia.

M. Y. M. Zuhri, Advanced Engineering Materials and Composites Research Centre, Department of Mechanical and Manufacturing Engineering, Universiti Putra Malaysia, 43400 UPM Serdang, Selangor, Malaysia.

(C) The Authors. Published by Blue Eyes Intelligence Engineering and Sciences Publication (BEIESP). This is an open access article under the CC BY-NC-ND license (http://creativecommons.org/licenses/by-nc-nd/4.0/)
Barrier (MDB) for the dynamic test of side impact test procedure to improve the side impact test [3]. Car manufacturers believe that the side-door impact beam can prevent the door intrusion into passenger's compartment simultaneously can reduce serious injury and fatality [4].

Side-door impact beam gives an opportunity to engineers and researchers to study and design the best side-door impact beam that can improve the safety of the vehicle during side impact collision. There were many studies involving cross section geometry for the side-door impact beam such as by Abdollah and Hassan, studied the different cross section with different material and found that aluminium square beam can replace circular high strength steel from the results of Charpy impact test [5]. In contrary, Nichit and Batu studies the same cross section with the carbon steel AISI 1010 material and found that I-beam and square beam is the best solution to replaced circular beam where I-beam was better compared to square beam by reducing the weight up to $17 \%$ and increased the bearing load up to $34 \%$ [6]. This was supported by Lashlem et al. where the impact test shows that I-beam was better than circular beam, II-beam and open channel W-beam was better than I-beam [7]. Fig. 1 shows the cross section studied by the researchers to compare the geometries for the side-door impact beam.

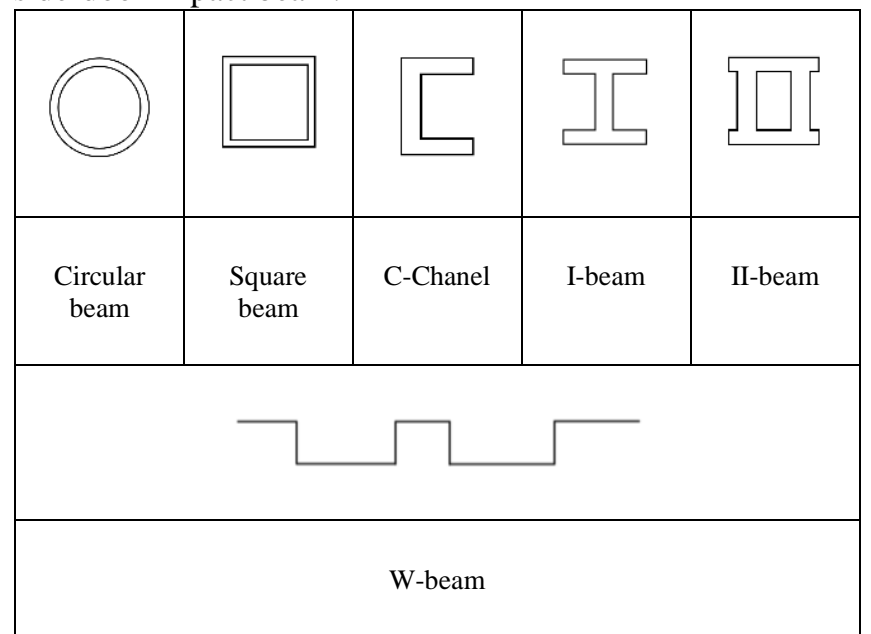

Fig. 1: Geometry studied for the automotive side-door impact beam

There are rules and regulations that need to follow by the manufacturers as the automotive industry progresses and one of them is to reduce the emission to the lowest level as the targeted emission emitted by 2020 for new passenger vehicle is an average of $95 \mathrm{~g} \mathrm{CO}_{2} / \mathrm{km}$ [8], [9]. This can be achieved by reducing the vehicle weight as suggested by Ishikawa et al. with the value of $20 \mathrm{~g} \mathrm{CO}_{2} / \mathrm{km}$ reduction for each $100 \mathrm{~kg}$ vehicle weight reduction [10].

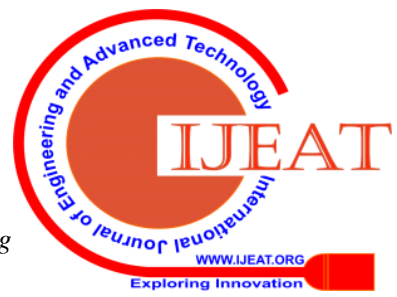




\section{Conceptual Design of New Bio-inspired Automotive Side-Door Impact Beam}

Weight reduction can be achieved by changing the conventional material to lighter material without sacrificing their purposes. From metal, metal alloy, aluminium, magnesium, fiber glass composites, carbon glass composites and natural fiber composites, it can replace the current materials to reduce the weight depend on their function and purposes [11]. There are plenty of researches in natural fiber composites that results in lighter materials and can be used in automotive vehicle such as door inner panel, seat covering, trunk panel, insulation and others [12], [13].

Natural fiber composites are lightweight, low cost, can be recycle, and environmentally friendly. Mohammed et al. listed the manufacturers that used natural fiber composites as their automotive components especially in car interior parts with Daimler Chrysler leads by producing 50 components for their Mercedes Benz E-class while BMW Group use 10000 tonnes of natural fibers in 2004 [13], [14]. Automotive industries taking a big step on using natural fiber composites not only because of their lightweight and improvement of the fuel consumption, but natural fiber composites can be recycled and safe to disposed [15]. Numerous researches on the natural fiber composites have been done by researchers around the world to improve their weaknesses such as lower mechanical properties, poor fire resistance and high water absorption [14]. Researchers are trying to improve the weaknesses of the natural fiber composites by modifying their physical and chemical properties, modifications of the matrix, and study the processing techniques for the improvement [16].

In conceptual design, Shekhar et al. generate the design concepts of transformable chair using Theory of Inventive Problem Solving (TRIZ) method [17]. In the other hand, using integrated method, Mansor et al. used TRIZ Morphological Chart - Analytic Hierarchy Process method for parking brake lever, Mastura et al. generate the design concepts of anti-roll bar using integrated method of TRIZ Blue Ocean Strategy - Morphological chart, and Azammi et al. developed conceptual design for engine mounting using TRIZ - Morphological Chart - Analytic Network Process method [18 - 20]. The integrated method shows the systematic process in generating idea for the design concepts in new product development.

Among the challenges in conceptual design stage is to get the numerical data to evaluate the conceptual solutions. Hence, this paper proposes the use integrated method of TRIZ (Function Oriented Search) - Biomimetics to generate design concept ideas and then using the final element analysis (FEA) method to evaluate each conceptual design performance. Since the aim of this study is to distinguish the performance of the proposed geometry, all geometry has been assigned to use the similar type of material which is kenaf reinforced polypropylene composites. The results will show the performance of the geometry that mimicking nature using FEA method.

\section{METHODOLOGY}

Fig. 2 shows the methodology used in this study that begins with the idea generation technique using the integrated method of TRIZ (FOS) - Biomimetics to develop the design concepts of the side-door impact beam. The generated designs then were analyzed using finite element analysis (FEA) method to compare their performance. Finally, the results obtained from the analysis were compared to see their performances of biomimicking nature in designing the new side-door impact beam.

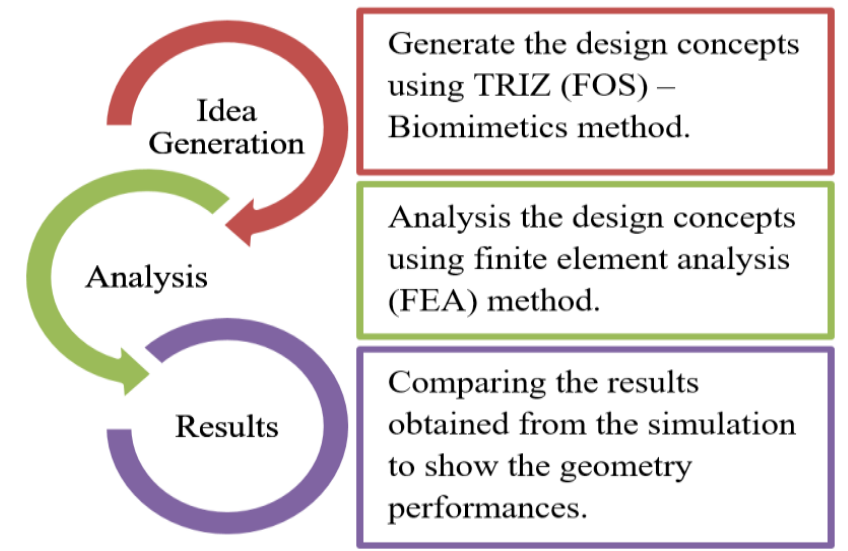

Fig. 2: The framework of the overall research

\section{A. Idea Generation Techniques of TRIZ (Function Oriented Search) - Biomimetics method}

The TRIZ Function-Oriented Search (TRIZ (FOS)) is one of the TRIZ tools that suggest to find any existing technology to solve the initial problem [21]. In other words, TRIZ (FOS) is a technology transfer from any model based on analogical thinking to the same application context [22]. Technology development that adapts from nature to solve engineering problems is called biomimicry or biomimetics [23]. Lists of successful biomimetic design include the Shinkansen bullet train from Kingfisher's beak, the Fastskin swimsuit from, and the Velcro zip [24], [25]. The technology transfer from nature into engineering as known as biomimetics successfully shows the idea can be developed to solve engineering problems.

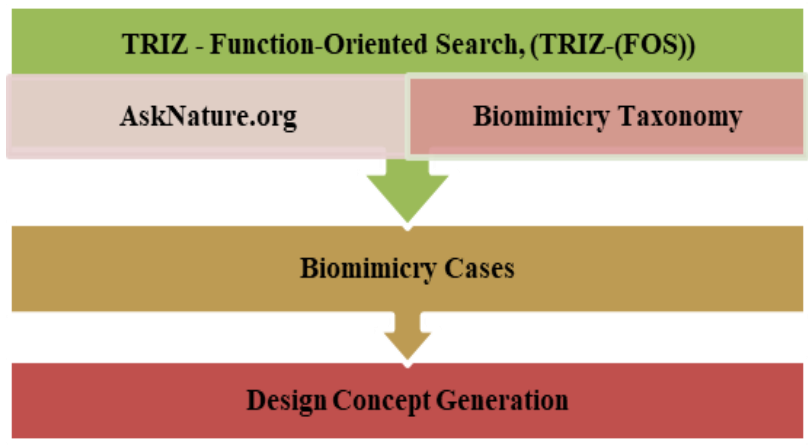

Fig. 3: Framework of TRIZ (FOS)-Biomimetics method.

Fig. 3 shows the integrated TRIZ (FOS)-Biomimetics method that proposed in this study to generate ideas in transferring the technology in nature to solve engineering problems. Function oriented search is a term to find a keyword to solve the initial solutions. In this framework, the keywords can be type in the search button or using the Biomimicry Taxonomy to find the biomimicry cases [26]. The website will then list the biomimicry cases and engineers need to filter the cases and go through the ideas in solving the 
initial engineering problem and generate relevant concepts of nature suggested by the cases.

\section{B. Analysis of the New Bio-inspired Design Beam}

The new bio-inspired design of the side-door impact beam then were analyzed using FEA method to study the performance of different design concepts that generated from the previous stage. In this stage, the aim of the impact simulation on the new side-door impact beam is to compare the performance of the new generated idea bio-inspired side-door impact beam. The performance includes the maximum stress. Maximum deformation and energy absorbed by the beam. Besides that, the weight of the new design can be obtained from the $3 \mathrm{D}$ modelled with that differentiate the weight difference between the design concepts generated. Fig. 4 shows the drawing of the simulation setup for the impact analysis using FEA method adapted from Cheon et al. while fig. 5 shows the 3D model used in this study. The length of the beam is $507 \mathrm{~mm}$ with the outer diameter of $32 \mathrm{~mm}$ while the impactor is $125 \mathrm{~mm}$ length with $50 \mathrm{~mm}$ diameter. The material of the impactor is stainless steel [27]. The results of the FEA were recorded to show the performance of each design concepts. It is then depending on the engineers to choose the best design for the new beam that mimicking nature.

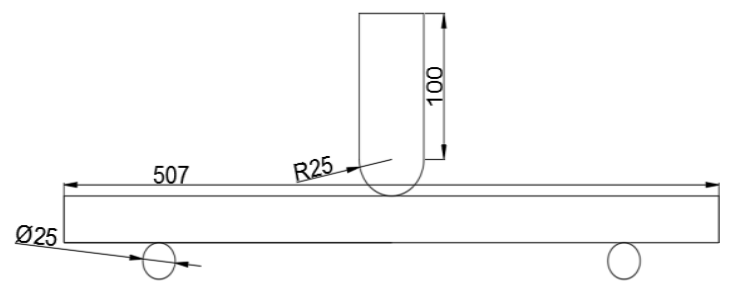

Fig. 4: Simulation setup for the impact analysis of new side-door impact beam

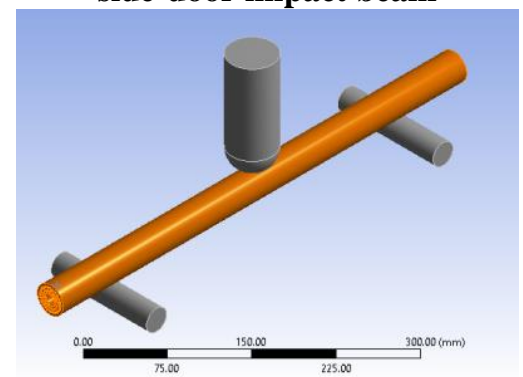

Fig. 5: 3D-modelling of the simulation setup.

\section{RESULTS AND DISCUSSION}

This study begins with idea generation technique to find the design that can imitate the nature technology into the new design of side-door impact beam. In this step, the website of asknature.org were used to find and select the biomimicry cases that can provide ideas to the initial engineering problems. Users can type the engineering keyword to perform the biomimetics search or use the biomimicry taxonomy keywords that related to the engineering problems and go through the biomimicry cases that can give initial idea to the problems. In this study, four keywords from biomimicry taxonomy were used to find the initial idea which is energy, compression, impact and fracture/rupture. From the results in table 1 , it shows the numbers of biological cases and inspired ideas for each keyword. The lists of the biological cases and inspired ideas maybe the same but in different function of the keywords. Users need to go through and get an initial idea from the biological's cases listed to generate the design concepts of the new side-door impact beam.

Table 1: Biological strategies and inspired ideas using keywords.

\begin{tabular}{l|cccc}
\hline Function & Energy & Compression & Impact & $\begin{array}{c}\text { Fracture/ } \\
\text { Rupture }\end{array}$ \\
\hline $\begin{array}{l}\text { Biological } \\
\text { Strategies }\end{array}$ & 48 & 65 & 57 & 47 \\
$\begin{array}{l}\text { Inspired } \\
\text { Ideas }\end{array}$ & 1 & 3 & 4 & 4 \\
\hline
\end{tabular}

Table 2 shows the design concepts generated from the biomimicry cases where it is based on three different biological cases in asknature.org which is from toucan beak, pomelo peel and hedgehog spine. In this study, two design concepts namely design concept 1 (DC1) and DC2 were generated from the Toucan beak, two design concepts, DC3 and DC4 were generated from pomelo peel and DC5 were generated from the hedgehog spine. In table 2, it shows different type of cross-section generated for the new bio-inspired side-door impact beam. Different cross-section design of the new side-door impact beam will give different performance when it is simulate using FEA method in the next step.

Table 2: Cross-section of the bio-inspired design for the new side-door impact beam using TRIZ (FOS)-Biomimetics method.

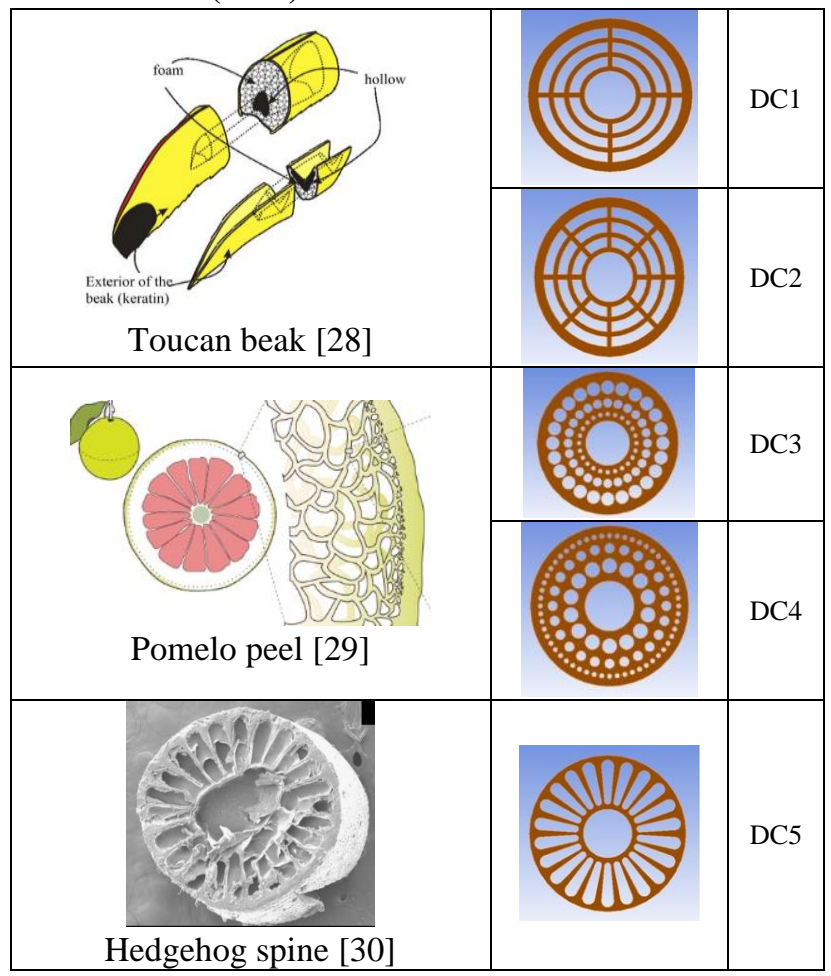

Fig. 6 shows the meshing model of the impact analysis on the new side-door impact beam and also the deformation of the beam under impact load by the impactor. The impactor is made from stainless steel that impact the new side-door impact beam. The simulation used the same configuration of the impact analysis such as time, boundary conditions and load from the impactor.

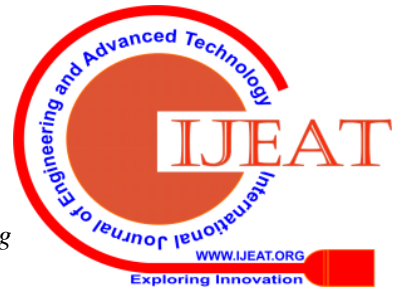


The difference is only the cross-section of the beam as shown in table 2. Fig. 7 shows the deformation during the impact analysis. The deformation of the beam was recorded to compare the differences between design concepts. Besides the deformation, stress and energy absorbed were also recorded during the analysis while weight of the beam was got from the 3D model data.

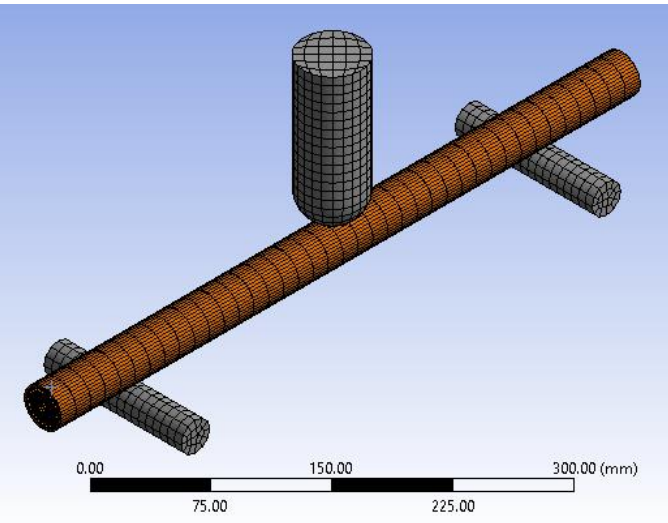

Fig. 6: Mesh model of the impact analysis.

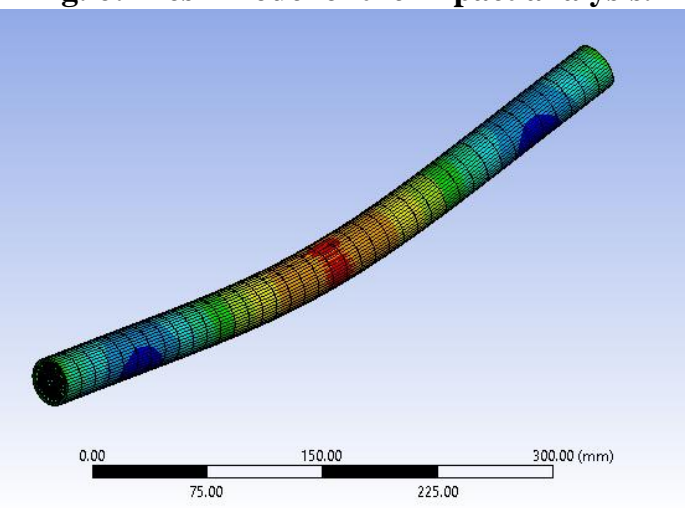

Fig. 7: Deformation of the impact analysis.

Fig. 8 shows the graph deformation of the new bio-inspired side-door impact beam for DC1 to DC5. It can be seen that the most deform beam is DC1 with the value of $28.363 \mathrm{~mm}$ followed by DC4 with the value of $26.529 \mathrm{~mm}$. From the figure, DC2, DC3 and DC5 are almost the same with the deformation value of $23.834 \mathrm{~mm}, 24.012 \mathrm{~mm}$ and $23.892 \mathrm{~mm}$ respectively. From the maximum deformation analysis, the least value design to deform is DC2. Ghadianlou and Abdullah found that circular beam with rib can reduce the deflection of the beam compared to the circular beam without rib [31]. The result was supported by Lashlem et al., where II-beam as in fig. 1 can reduce beam deflection compared to the circular beam [7]. In other words, additional rib in the beam minimize the deflection of the beam. Graph of the beam stress was shown in fig. 9. In the early stage of impact, it can be seen that higher stress occur on DC3 compared to other design concepts. At the end of the graph, the stress of DC4 increases abruptly compared to others. DC2 and DC5 shows a steady stress from the beginning of the impact until the end with the maximum stress value of $225.68 \mathrm{MPa}$ and 204.86 MPa respectively. The maximum stress value of the impact analysis was recorded and shown in table 3, shows that DC5 has the lowest maximum stress compared to others. In table 3 , total energy absorbed by the beam shows that the least absorbed energy was by DC2 while the highest absorbed energy was DC4. Table 3 summarized the performance results and the weight of the design concepts for the new bio-inspired side-door impact beam. This study shows that nature technology can be transferred to solve engineering problems. Therefore, the results obtained is not to choose the best design based on the performance results of FEA method but to show that difference design concept ideas generate different performance to the new proposed design.

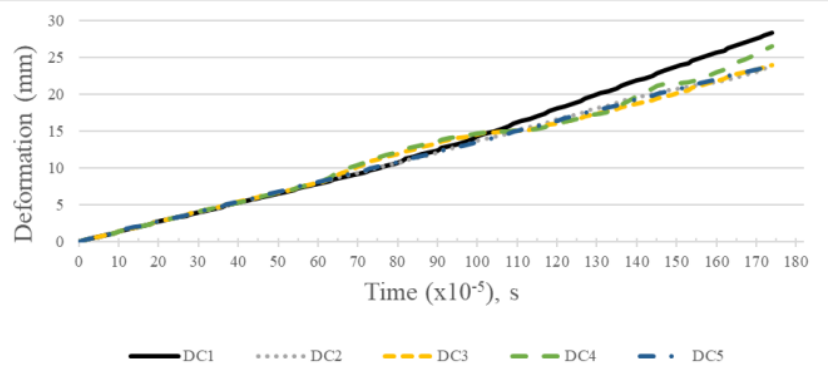

Fig. 8: Graph deformation of the beam vs time.

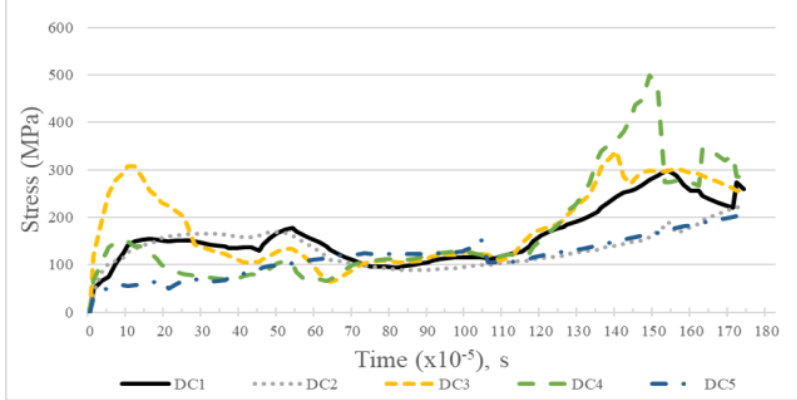

Fig. 9: Graph stress of the beam vs time.

Table 3: Results of the finite element analysis of the new bio-inspired side-door impact beam.

\begin{tabular}{|c|c|c|c|c|c|}
\hline & DC1 & DC2 & DC3 & DC4 & DC5 \\
\hline $\begin{array}{l}\text { Maximum } \\
\text { deformation } \\
(\mathrm{mm})\end{array}$ & 28.363 & 23.834 & 24.012 & 26.529 & 23.892 \\
\hline $\begin{array}{c}\text { Maximum } \\
\text { stress }(\mathrm{MPa})\end{array}$ & 298.42 & 225.68 & 340.03 & 499.27 & 204.86 \\
\hline $\begin{array}{c}\text { Energy } \\
\text { Absorption } \\
(\mathrm{J}) \\
\end{array}$ & 47.381 & 39.655 & 89.525 & 91.215 & 53.195 \\
\hline Weight (kg) & 0.39798 & 0.40436 & 0.47068 & 0.51711 & 0.34400 \\
\hline
\end{tabular}

\section{CONCLUSIONS}

As a conclusion, this study shows that the integrated method of TRIZ (FOS) - biomimetics can generate ideas to the engineers in transferring the nature technology to solve engineering problem. In this study, five design concepts namely DC1 to DC5 were generated using this method mimicking the toucan beak, pomelo peel and hedgehog spine.

The generated design concepts were then analyzed using finite element analysis method to study their performances including the deformation, stress and energy absorption. The lowest beam deformation is from DC2 with the value of $23.834 \mathrm{~mm}$ while the highest deformation goes to DC1 with the value of $28.363 \mathrm{~mm}$. The highest value of maximum stress of the beam occur on DC4 with $499.27 \mathrm{MPa}$. For energy absorption, DC4 is the highest while DC2 is the lowest with the value of $91.215 \mathrm{~J}$ and $39.655 \mathrm{~J}$ respectively.

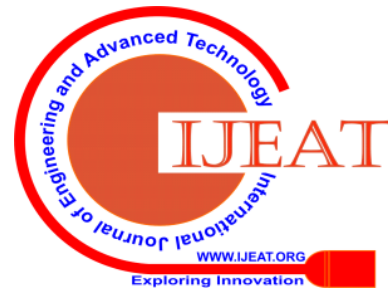


Hence, the aim of this study is achieved where the idea generation technique for mimicking the nature into engineering were successful using the integrated method of TRIZ (FOS) and biomimetics. The performances of the generated design also been studied using FEA method and shows that different geometry of the designs give different performance results. The strategy proposed in this study can help engineers to generate ideas to solve engineering problems based on biological cases and inspired ideas from the nature.

\section{ACKNOWLEDGMENT}

The authors would like to thank Centre for Advanced Research on Energy (CARe), Universiti Teknikal Malaysia Melaka and Centre for Research and Innovation Management (CRIM), Universiti Teknikal Malaysia Melaka for providing the financial support, as well as Universiti Putra Malaysia for the facilities support and last but not least Ministry of Education Malaysia for providing scholarship to the principal author to carry out this research project.

\section{REFERENCES}

1. C. E. Hedeen and D. D. Campbell, "Side Impact Structures," 1969 Int. Automot. Eng. Congr. Expo., 1969.

2. C. J. Kahane, "An Evaluation of Side Structure Improvements in Response to Federal Motor Vehicle Safety Standard 214," Washington DC, 1982.

3. J. Jones, "National Highway Traffic Safety Administration Laboratory Test Procedure for FMVSS No.214, Dynamic Side Impact Protection Moving Deformable Barrier Test Requirements," 2012.

4. H. Tanabe, K. Yamazaki, H. Akada, A. Miyasaka, and T. Iwasaki, "High-strength steel tubes for automobile door impact beams," 1995.

5. M. F. Abdollah and R. Hassan, "Preliminary design of side door impact beam for passenger cars using aluminium alloy," J. Mech. Eng. Technol., 2013, vol. 5, no. 1, pp. 11-18.

6. Y. K. Nichit and A. K. Battu, "Development of Side Door Intrusion Beam of Passenger Car For Maximum Bending Load,” Int. J. Sci. Adv. Res. Technol., 2017, vol. 3, no. 8, pp. 1-6.

7. A. A. Lashlem, D. A. Wahab, S. Abdullah, and C. H. Cheharon, "The Effect of Geometry in End-of-Life Vehicle Recovery of Safety Beams," Appl. Mech. Mater., 2014, vol. 663, pp. 614-621.

8. S. Malfettani, C. Lodi, T. Huld, and P. Bonnel, "Latest Developments on the European Eco-innovation Scheme for Reducing $\mathrm{CO}_{2}$ Emissions from Vehicles: Average Input Data for Simplified Calculations," Transp. Res. Procedia, 2016, vol. 14, pp. 4113-4121.

9. A. Strass, "Power semiconductor and packaging trends in vehicle electrification," World Electr. Veh. J., 2015, vol. 7, no. 2, pp. 250-260.

10. T. Ishikawa et al., "Overview of automotive structural composites technology developments in Japan," Compos. Sci. Technol., 2018, vol. 155, pp. 221-246.

11. E. Ghassemieh, "Materials in Automotive Application, State of the Art and Prospects," in New Trends and Developments in Automotive Industry, Marcello Chiaberge, Ed. InTech, 2011, pp. 365-394.

12. C. Alves, A. Silva, L. Reis, P. Ferro, and M. Freitas, "Sustainable Design of Automotive Components Through Jute Fiber Composites: an Integrated Approach," in New Trends and Developments in Automotive Industry, M. Chiaberge, Ed. InTech, 2011, pp. 223-254.

13. J. Holbery and D. Houston, "Natural-fibre-reinforced polymer composites in automotive applications," J. Miner. Met. Mater. Soc., 2016, vol. 58, no. 11, pp. 80-86.

14. L. Mohammed, M. N. M. Ansari, G. Pua, M. Jawaid, and M. S. Islam, "A Review on Natural Fiber Reinforced Polymer Composite and Its Applications," Int. J. Polym. Sci., 2015, pp. 1-15.

15. T. Gurunathan, S. Mohanty, and S. K. Nayak, "A review of the recent developments in biocomposites based on natural fibres and their application perspectives," Compos. Part A Appl. Sci. Manuf., 2015, vol. 77, pp. $1-25$.

16. A. Gholampour and T. Ozbakkaloglu, "A review of natural fiber composites: properties, modification and processing techniques, characterization, applications," J. Mater. Sci., 2020, vol. 55, no. 3, pp. 829-892.
17. K. N. Shekhar, J. Reddy, and G. P. Pradeep, "Conceptual Development of a Transformable Chair Using TRIZ," Int. J. Des. Manuf. Technol., 2015, vol. 9, no. 1, pp. 29-37.

18. M. R. Mansor, S. M. Sapuan, E. S. Zainudin, A. A. Nuraini, and A Hambali, "Conceptual design of kenaf fiber polymer composite automotive parking brake lever using integrated TRIZ-Morphological Chart-Analytic Hierarchy Process method," Mater. Des., 2014, vol. 54, pp. 473-482.

19. M. T. Mastura, S. M. Sapuan, M. R. Mansor, and A. A. Nuraini, "Conceptual design of a natural fibre-reinforced composite automotive anti-roll bar using a hybrid approach," Int. J. Adv. Manuf. Technol., 2017, vol. 91, no. 5-8, pp. 2031-2048.

20. A. M. N. Azammi, S. M. Sapuan, M. R. Ishak, and M. T. H. Sultan, "Conceptual design of automobile engine rubber mounting composite using TRIZ-Morphological chart-analytic network process technique," Def. Technol., 2018, vol. 14, no. 4, pp. 268-277.

21. S. S. Litvin, "New TRIZ-Based Tool - Function-Oriented Search (FOS)," in TRIZ Future Conference 2004, 2004, pp. 505-508.

22. T. Montecchi and D. Russo, "FBOS: Function/Behaviour-Oriented Search," Procedia Eng., 2015, vol. 131, pp. 140-149.

23. J. F. V. Vincent, "Biomimetics - A review," Proc. Inst. Mech. Eng. Part H J. Eng. Med., 2009, vol. 223, no. 8, pp. 919-939.

24. P. E. Fayemi, N. Maranzana, A. Aoussat, and G. Bersano, "Bio-inspired design characterisation and its links with problem solving tools," in Proceedings of International Design Conference, DESIGN, 2014, pp. 173-182.

25. B. Bhushan, "Biomimetics: Lessons from Nature - an overview," Philos. Trans. R. Soc. A Math. Phys. Eng. Sci., 2009, vol. 367, no. 1893, pp. 1445-1486.

26. Biomimicry Institute, “asknature," 2006. [Online]. Available: https://asknature.org/. [Accessed: 20-Jun-2018].

27. S. S. Cheon, D. G. Lee, and K. S. Jeong, "Composite side-door impact beams for passenger cars," Compos. Struct., 1997, vol. 38, no. 1-4, pp. 229-239.

28. Y. Seki, M. S. Schneider, and M. A. Meyers, "Structure and mechanical behavior of a toucan beak," Acta Mater., 2005, vol. 53, pp. 5281-5296.

29. J. Ortiz, G. Zhang, and D. A. McAdams, "A Model for the Design of a Pomelo Peel Bioinspired Foam,” J. Mech. Des., 2018, vol. 140, no. 11, pp. $1-5$.

30. J. F. V. Vincent, "Survival of the cheapest," Mater. Today, 2002, vol. 5, no. 12 , pp. $28-41$.

31. A. Ghadianlou and S. Bin Abdullah, "Crashworthiness design of vehicle side door beams under low-speed pole side impacts," Thin-Walled Struct., 2013, vol. 67, pp. 25-33.

\section{AUTHORS PROFILE}

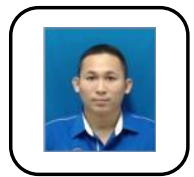

Mohd Adrinata bin Shaharuzaman, received his B.Eng. (Mechanical - Automotive) in 2007 and M.Eng. Mechanical in 2010 from Universiti Teknologi Malaysia (UTM). He started his career at Universiti Teknikal Malaysia Melaka since 2007 as a tutor in the Department of Automotive, Faculty of Mechanical Engineering. His research interests include automotive technology, automotive safety (crash test), biocomposites and material selection.

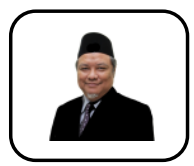

S.M. Sapuan is a professor of composite materials at Universiti Putra Malaysia. He earned his B.Eng degree in Mechanical Engineering from University of Newcastle, Australia in 1990, MSc from Loughborough University, UK in 1994 and Ph.D from De Montfort University, UK in 1998. His research interests include natural fiber composites, materials selection and concurrent engineering. To date he has authored or co-authored more than 1300 publications international journals (629 papers), books (17), edited books (13), chapters in books (91) and conference proceedings/seminars (597 papers).

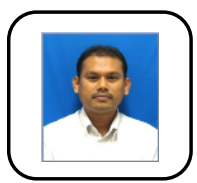

Muhd Ridzuan Bin Mansor, received his B.Eng (Hons.) in 2001 from Universiti Teknologi Malaysia (UTM), M.Sc. in Manufacturing System Engineering in 2007 from Coventry University, United Kingdom and Ph.D in Mechanical Engineering from Universiti Putra Malaysia in 2015. He started his career at Universiti Teknikal Malaysia Melaka since 2005 as a tutor in the Department of Automotive,

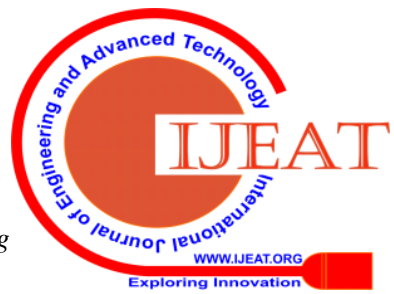




\section{Conceptual Design of New Bio-inspired Automotive Side-Door Impact Beam}

Faculty of Mechanical Engineering. His research interests include biocomposites, concurrent design, automotive technology and manufacturing system engineering.

Dr. Mohd Zuhri Mohamed Yusoff is currently a senior lecturer in Department of Mechanical and Manufacturing Engineering, Universiti Putra Malaysia (UPM). His areas of interest are in composite materials and lightweight structures. He is a member of Board of Engineers Malaysia (BEM), Majlis Rekabentuk Malaysia (MRM), International Association of Advanced Materials (IAAM), International Association of Engineers (IAENG) and International Society for Development and Sustainability (ISDS). To date, he has authored and co-authored more than 20 papers including journal and conference papers. He has also been awarded the sponsorship for participate in JENESYS program from the Government of Japan. 